\title{
A UNIVERSALIZAÇÃO DOS DIREITOS SOCIAIS E SUA RELEVÂNCIA PARA O EXERCÍCIO E CONCREÇÃO DA CIDADANIA
}

\author{
JUVÊNCIO BORGES SILVA ${ }^{\dagger}$ \\ FABIANA ZACARIAS ${ }^{+\dagger}$ \\ LEONARDO AQUiNO MOREIRA GUIMARÃES ${ }^{++}$
}

RESUMO: Este artigo tem como objetivo analisar os direitos fundamentais sociais, consagrados na Constituição Federal de 1988, como dimensão dos direitos humanos. A pesquisa parte do estudo dos direitos humanos e da constitucionalização dos direitos sociais. Aborda a judicialização dos direitos fundamentais, principalmente no que se refere à legitimidade do Poder Judiciário para a implementação de políticas públicas, diante da escassez de recursos financeiros e orçamentários, analisando-se o princípio da cláusula da reserva do possível, o direito ao mínimo existencial, o princípio do não retrocesso social e a garantia da dignidade humana. $\mathrm{O}$ trabalho faz uma análise dos aspectos teóricos e práticos, para demonstrar importância da universalização dos direitos sociais para a garantia do exercício da cidadania, orientando-se, para tanto, pelo método analítico-dedutivo.

Palavras-ChaVe: Direitos humanos; Diretos fundamentais sociais; Reserva do possível; Mínimo existencial; Não retrocesso social.

\footnotetext{
+ Pós-doutor em Direito pela Faculdade de Direito da Universidade de Coimbra; Doutor em Sociologia pela Universidade Estadual Júlio de Mesquita Filho - UNESP; Mestre em Sociologia pela Universidade de Campinas - UNICAMP; Graduado em Direito pela Faculdade de Direito de Franca; Graduado em Ciências Sociais pela Faculdade de Filosofia de Passos - FAFIPA.

+ Mestre em Direitos Coletivos e Cidadania na "Universidade de Ribeirão Preto" UNAERP - Ribeirão Preto/SP; Professora Universitária.

${ }^{++t}$ Mestrando em Direito Coletivo e Cidadania na "Universidade de Ribeirão Preto" UNAERP - Ribeirão Preto/SP.
} 
ABSTRACT: This article aims to analyze the fundamental social rights, enshrined in the 1988 Federal Constitution, as a human rights dimension. The research herein is based on the study of both human rights and the constitutionalization of social rights. This article approaches the judicialization of fundamental rights, especially regarding the legitimacy of the Judiciary for the implementation of public policies, given the lack of financial and budgetary resources, as well as analyzes not only the principle of the reservation of the possible clause, but also the right to the minimum existential, the principle of the non-social-retrogression and the guarantee of human dignity. Finally, the paper will analyze its theoretical and practical aspects, in order to demonstrate the importance of universalizing social rights as a guarantee of the citizenship exercise. Important to mention that this article was guided by the analyticaldeductive method.

KEYWORDS: Human Rights; Fundamental social rights; Reservation of the possible; Minimum existential; Non-social-retrogression. 


\section{INTRODUÇÃo}

Os direitos fundamentais sociais foram consagrados no artigo $6^{\circ}$ da Constituição Federal de 1988. Tendo em vista sua fundamentalidade e a disposição do $\S 1^{1}$, artigo 5ํㅡㄹ , da Constituição Federal de 1988 - de que as normas definidoras dos direitos e garantias fundamentais possuem aplicação imediata - analisou-se a necessidade de respeito ao conteúdo mínimo dos direitos sociais.

A previsão constitucional, além da auto aplicabilidade, revela a indisponibilidade dos direitos sociais previstos no artigo $6^{\circ}$, segundo a qual "são direitos sociais a educação, a saúde, a alimentação, o trabalho, a moradia, o lazer, a segurança, a previdência social, a proteção à maternidade e à infância e a assistência aos desamparados".

A obrigação jurídica resultante destes direitos sociais recai sobre os poderes públicos que dependem, econômica e financeiramente, de recursos disponíveis para implementar políticas públicas com vistas à concretização das "normas programáticas". Sucede, assim, o dever do Estado de concretizar os direitos sociais através de prestações positivas, com vistas à igualdade material e social.

Neste contexto, face a limitação dos recursos estatais, a não efetivação dos direitos sociais resulta na judicialização: o Poder Judiciário adquire legitimidade para garantir a efetividade das normas constitucionais e concretizar a justiça social.

Abordou-se o papel do Poder Judiciário na efetivação dos direitos sociais prestacionais face a cláusula da reserva do possível e o mínimo existencial, com vistas ao não retrocesso social e garantia da Dignidade da Pessoa Humana. Por derradeiro, fez-se uma análise dos direitos sociais como essência para a garantia da igualdade e exercício da cidadania.

Utilizou-se o método analítico-dedutivo como forma de abordagem da pesquisa e o procedimento empregado como técnica foi a revisão de literatura pertinente à temática proposta, valendo-se, para tanto, da doutrina, jurisprudência, artigos científicos e legislação, de modo a ter uma percepção real e conclusão geral sobre o tema.

\section{A gARANTIA DE DIREITOS HUMANOS}

A historicidade dos direitos humanos revela seu nascimento gradual: "nem todos de uma vez e nem de uma vez por todas" ${ }^{1}$ Embora a

${ }^{1}$ BOBBIO, Norberto. A Era dos Direitos. Tradução: Carlos Nelson Coutinho. Rio de Janeiro: Campus, 1992, p. 05. 
construção histórica, jurídica e filosófica sobre os direitos humanos traga a noção de que os direitos e liberdades são inerentes aos indivíduos, muitos destes direitos foram regulamentados pelos Estados no pósguerra, como forma de proteção contra os abusos e arbítrios praticados pelo Estado - ao tempo que o Estado assegura a liberdade, deve garantir também o pleno exercício de direitos dos seus cidadãos, iguais em direitos e liberdades.

A concepção contemporânea de direitos humanos, marcada pela universalidade e indivisibilidade, foi introduzida pela Declaração Universal de 1948. Nesse sentido, Flávia Piovesan:

Universalidade porque clama pela extensão universal dos direitos humanos, sob a crença de que a condição de pessoa é o requisito único para a titularidade de direitos, considerando $\mathrm{o}$ ser humano como um ser essencialmente moral, dotado de unicidade existencial e dignidade, esta como valor intrínseco à condição humana. Indivisibilidade porque a garantia dos direitos civis e políticos é condição para a observância dos direitos sociais, econômicos e culturais e vice-versa. Quando um deles é violado, os demais também o são. Os direitos humanos compõem, assim, uma unidade indivisível, interdependente e inter-relacionada, capaz de conjugar o catálogo de direitos civis e políticos com o catálogo de direitos sociais, econômicos e culturais. Sob esta perspectiva integral, identificam-se dois impactos: a) a inter-relação e interdependência das diversas categorias de direitos humanos; e b) a paridade em grau de relevância de direitos sociais, econômicos e culturais e de direitos civis e políticos. ${ }^{2}$

2 PIOVESAN, Flávia. Proteção dos direitos sociais: desafios do ius commune sulamericano. Rev. TST, Brasília, v. 77, n. 4, 2011, p. 105 . Disponível em: $<$ http://siabi.trt4.jus.br/biblioteca/acervo/Doutrina/artigos/Revista do Tribunal Superior do Trabalho/2011/n 4/Proteção dos direitos sociais - desafios do ius commune sul-americano.pdf>. Acesso em: 15 mar. 2017. 
"Se a Segunda Guerra significou a ruptura com os direitos humanos, o pós-guerra deveria significar a sua reconstrução." ${ }^{3}$ - não se admitindo a "existência de uma soberania absoluta e irrestrita, em decorrência da necessidade dos Estados buscarem a atuação de um conjunto em determinadas políticas, exigências da nova ordem mundial". ${ }^{4} \mathrm{~A}$ isonomia passou a ladear os direitos humanos, buscando sempre a limitação do poder estatal para garantir a liberdade individual.

Para Norberto Bobbio $^{5}$, a problemática em relação aos direitos humanos é sua proteção, pois exige maior atuação dos Estados não apenas consagrá-los nas constituições, mas garantir o respeito e pleno desenvolvimento da dignidade da pessoa humana.

Portanto, o Direito Internacional dos Direitos Humanos começa a se desenvolver a partir da Declaração de 1948, através da adoção de instrumentos internacionais de proteção, que lhes confere unidade valorativa decorrente da universalidade e indivisibilidade.

O Brasil, seguindo a evolução de países signatários da Declaração Universal, consagra o Estado Democrático de Direito com a promulgação da Constituição Federal de 1988. Adota como base principiológica o Princípio da Dignidade Humana, voltado "a indicar um sentido de direção que a Constituição busca imprimir à sociedade brasileira." 6

O Estado brasileiro, enquanto democrático e de direito, deve assegurar direitos fundamentais ${ }^{7}$ e, em última análise, garantir a

3 PIOVESAN, Flávia. Proteção dos direitos sociais: desafios do ius commune sulamericano. Rev. TST, Brasília, v. 77, n. 4, 2011, p. 104.

${ }^{4}$ GOMES, Eduardo Biacchi. Blocos econômicos: solução de controvérsias, uma análise comparativa a partir da União Europeia e Mercosul. 3. ed. rev. atual. Curitiba: Juruá: 2010, p. 140.

${ }^{5}$ Ensina Norberto Bobbio que: "Não se trata de saber quais e quantos são esses direitos, qual é a sua natureza e seu fundamento, se são direitos naturais ou históricos, absolutos ou relativos, mas sim qual é o modo mais seguro para garanti-los, para impedir que, apesar das solenes declarações, eles sejam continuamente violados", Cf. GOMES, Eduardo Biacchi. Blocos econômicos: solução de controvérsias, uma análise comparativa a partir da União Europeia e Mercosul. 3. ed. rev. atual. Curitiba: Juruá: 2010, p. 45.

${ }^{6}$ LAFER, Celso. A internacionalização dos direitos humanos: constituição, racismo e relações internacionais. São Paulo: Manole, 2005, p. 14.

7 Segundo Ingo Wolfgang Sarlet, o termo "direitos fundamentais" aplica-se aos direitos do ser humano reconhecidos e positivados na esfera do direito constitucional positivo de determinado Estado; enquanto os direitos humanos, por serem inerentes ao homem, independem de vinculação à ordem constitucional, pois aspiram à validade 
igualdade material para promoção do bem-estar social. A Constituição Federal assume importância para a fundamentalidade dos direitos humanos: sem o Estado, nem a proclamação, nem a concretização dos direitos fundamentais seria possível. Os direitos fundamentais são expressões da dignidade humana como seu valor essencial, inato e intrínseco.

Sinteticamente, "a Constituição é norma jurídica central no sistema e vincula a todos dentro do Estado, sobretudo os Poderes Públicos. E, de todas as normas constitucionais, os direitos fundamentais integram o núcleo normativo que, por variadas razões, deve ser especificamente privilegiado." 8

Portanto, em que pese entendimento em contrário, os direitos sociais têm natureza de verdadeiros direitos fundamentais:

Há que se fortalecer a perspectiva integral dos direitos humanos, que tem nos direitos sociais uma dimensão vital e inalienável, aprimorando os mecanismos de sua proteção e justiciabilidade, dignificando, assim, a racionalidade emancipatória dos direitos sociais como direitos humanos, nacional e internacionalmente garantidos. $^{9}$

A fundamentalidade dos direitos sociais "impõe respeito a um conteúdo básico e mínimo de direitos determinados, aquém do qual não se toleram contenções" ${ }^{\prime 10}$, garantindo o direito ao mínimo existencial.

universal. SARLET, Ingo Wolfgang. A eficácia dos Direitos Fundamentais. Uma teoria geral dos direitos fundamentais na perspectiva Constitucional. 10. ed. Porto Alegre: Livraria do Advogado, 2011, p. 29.

8 BARCELlOS, Ana Paula de. Neoconstitucionalismo, Direitos Fundamentais e Controle das Políticas Públicas. Revista de Direito Administrativo: Repositório FGV de Periódicos e Revistas, Rio de Janeiro, v. 240, 2005, p. 89.

9 PIOVESAN, Flávia. Proteção dos direitos sociais: desafios do ius commune sulamericano. Rev. TST, Brasília, v. 77, n. 4, 2011, p. 135.

${ }^{10}$ ROTHENBURG, Walter Claudius. Direitos Fundamentais e suas características. Revista de Direito Constitucional e Internacional, São Paulo, n. 8, 2000, p. 147. 


\section{ANÁLISE CONSTITUCIONAL DOS DIREITOS SOCIAIS}

Os direitos sociais estão previstos no artigo $6^{\circ}$ da Constituição Federal de 1988: educação, saúde, alimentação, trabalho, moradia, transporte, lazer, segurança, previdência social, proteção à maternidade e infância, assistência aos desamparados. ${ }^{11} \mathrm{O}$ texto constitucional inovou ao assegurar direitos sociais em capítulo próprio, no catálogo dos direitos fundamentais. Surge a segunda geração de direitos fundamentais: os direitos econômico-sociais, que disciplinam situações subjetivas, possibilitando aos indivíduos exigirem do Estado uma prestação ativa para garantir o seu próprio bem-estar.

"Trata-se com essa nova dimensão, não de se proteger contra o Estado, mas, sobretudo, de elaborar um rol de pretensões exigíveis do próprio Estado, que passa a ter que atuar para satisfazer tais direitos." 12 Sucede, pois, o dever do Estado de concretizar os direitos sociais através de prestações positivas de todos os órgãos do Estado, com vistas à justiça social e igualdade material. Nesse sentido, Ingo Sarlet:

[...] são uma densificação do princípio da justiça social, sendo que correspondem invariavelmente, a reivindicação das classes menos favorecidas, sobretudo a operária, a título de compensação em decorrência da extrema desigualdade que caracteriza suas relações com a classe empregadora, detentora do maior poderio econômico. ${ }^{13}$

A propósito, os preceitos constitucionais relativos a direitos sociais possuem força jurídica comum a todas as normas constitucionais imperativas, ademais:

[...] os direitos sociais surgiram juridicamente como prerrogativas dos segmentos mais desfavoráveis - sob a forma normativa de obrigações do Executivo, entre outros motivos porque, para que possam ser materialmente eficazes, tais direitos implicam uma intervenção ativa e continuada por parte dos poderes públicos. A característica básica dos direitos sociais está no fato de que, forjados numa linha oposta ao

11 Art. $6^{\text {o }}$ São direitos sociais a educação, a saúde, a alimentação, o trabalho, a moradia, o transporte, o lazer, a segurança, a previdência social, a proteção à maternidade e à infância, a assistência aos desamparados, na forma desta Constituição.

12 TAVARES, André Ramos. Direitos Fundamentais e suas características. Revista de Direito Constitucional e Internacional, São Paulo, n. 8, 2000, p. 421.

13 SARLET, Ingo Wolfgang. A eficácia dos direitos fundamentais. 8. ed., rev. e atual. Porto Alegre: Livraria do Advogado, 2007, p. 57. 


\section{A UNIVERSALIZAÇÃO DOS DIREITOS SOCIAIS E SUA RELEVÂNCIA PARA O EXERCÍCIO E CONCREÇÃO DA CIDADANIA}

paradigma kantiano de uma justiça universal, foram formulados dirigindo-se menos aos indivíduos tomados isoladamente como cidadãos livres e anônimos e mais na perspectiva dos grupos, comunidades, corporações e classes a que pertencem. Ao contrário da maioria dos direitos individuais tradicionais, cuja proteção exige apenas que o Estado jamais permita sua violação, os direitos sociais não podem simplesmente ser "atribuídos" aos cidadãos; cada vez mais elevados à condição de direitos constitucionais, os direitos sociais requerem do Estado um amplo rol de políticas públicas dirigidas a segmentos específicos da sociedade políticas essas que têm por objetivo fundamentar esses direitos e atender às expectativas por eles geradas com sua positivação. ${ }^{14}$

Nas palavras de José Joaquim Gomes Canotilho:

O entendimento dos direitos sociais, econômicos e culturais como direitos originários implica, como já foi salientado, uma mudança na função dos direitos fundamentais e põe com acuidade o problema da sua efectivação. Não obstante se falar aqui da efectivação dentro de uma "reserva do possível", para significar a dependência dos direitos econômicos, sociais e culturais não se reduz a um simples "apelo" ao legislador. Existe uma verdadeira imposição constitucional, legitimadora, entre outras coisas, de transformações econômicas e sociais na medida em que estas forem necessárias para a efectivação desses direitos (cfr. Artigos $2^{\circ}, 9^{\circ} / \mathrm{d}, 80^{\circ}$, $\left.81^{\circ}\right) \cdot{ }^{15}$

Por conseguinte, a obrigação jurídica dos direitos sociais recai sobre o poder público que depende, econômica e financeiramente, de recursos

${ }^{14}$ FARIA, José Eduardo. Os desafios do Judiciário. Revista USP. São Paulo, n. 21, p. 4757: Coordenadoria de Comunicação Social (CCS) / USP, 1994, p. 54.

${ }^{15}$ CANOTILHO, José Joaquim Gomes. Direito Constitucional e Teoria da Constituição. 7 ed. Coimbra: Almedina, 2003, p. 478. 
econômicos e financeiros disponíveis para implementar políticas públicas com vistas à concretização substancial das normas programáticas.

Para Jorge Miranda ${ }^{16}$ há uma relação necessária e constante entre a realidade constitucional e o estádio de efetividade das normas; entre a capacidade do Estado e da sociedade e os direitos derivados a prestações; entre os bens económicos disponíveis e os bens jurídicos deles inseparáveis.

Da não efetivação dos direitos humanos constitucionalmente assegurados, exsurge a judicialização dos direitos sociais.

\section{DIREITOS SOCIAIS E POLÍTICAS PÚBliCAS: A JUDICIALIZAÇÃO EM FACE DA OMISSÃO}

O legislador constituinte consagrou direitos e garantias fundamentais determinando, como meio de torná-los efetivos, a sua aplicação imediata. (Art. 5.,$\S 1 .^{\circ}$ da $\left.C R\right)^{17}$. A maior consequência disso é o aumento ou acúmulo das funções institucionais do Poder Judiciário.

“A Constituição de 1988, apesar dos seus limites, representou um passo significativo para a inclusão de novos sujeitos sociais na esfera da cidadania, bem como garantiu, ao menos no papel, direitos outrora reivindicados pelos movimentos sociais." 18

A promoção e proteção dos direitos sociais fundamentais exige ações estatais através de políticas públicas, como explica Ana Paula Barcellos:

A Constituição estabelece como um dos seus fins essenciais a promoção dos direitos fundamentais. As políticas públicas constituem o meio pelo qual os fins constitucionais podem ser realizados de forma sistemática e abrangente, mas envolvendo gasto de dinheiro público. Como se sabe os recursos públicos são limitados e é preciso fazer opção. As escolhas em matéria de gastos e políticas públicas não constituem um tema integralmente reservado à deliberação política; ao

${ }^{16}$ MIRANDA, Jorge. O regime dos direitos sociais. Revista de Informação Legislativa, Brasília, 2010, A. 47, n. 188, p. 34.

17 Art. $5^{\mathrm{o}}$. $\S 1^{\mathrm{o}}$ As normas definidoras dos direitos e garantias fundamentais têm aplicação imediata.

18 PERLATTO, Fernando. A Constituição de 1988: um marco para a História da Nova República brasileira. Contemporâneos, Revista de Artes e Humanidades, n. 3, novabril 2009. 


\section{A UNIVERSALIZAÇÃO DOS DIREITOS SOCIAIS E SUA RELEVÂNCIA PARA O EXERCÍCIO E CONCREÇÃO DA CIDADANIA}

contrário, o ponto recebe importante incidência das normas jurídicas constitucionais. ${ }^{19}$

A eficácia dos direitos sociais depende da harmonia do Poder Público - Executivo, Legislativo, Judiciário - e da tutela do Estado. Contudo, em razão da realidade jurídica, social e política e outros limites fáticos, principalmente de ordem econômica e orçamentária, os direitos sociais não são concretizados. Deste contexto sociopolítico, a reivindicação da tutela jurisdicional dos direitos sociais resulta na judicialização de "questões relevantes do ponto de vista político, social ou moral estão sendo decididas, em caráter final, pelo Poder Judiciário." 20

Em tempos da preponderância de valores constitucionais centrados na Dignidade Humana, a omissão política do Executivo e Legislativo, não pode ser corroborada pela omissão do Poder Judiciário. De acordo com o que ensina Rafael Thomaz de Oliveira e Clarissa Tassinari:

[...] nossa constituição vigente visa a ter, em si e por si mesma, uma capacidade de fomentar a transformação social, de modo que se propõe a estabelecer diretrizes, objetivos e fins a serem alcançados pelo Estado e pela sociedade, além de vincular o legislador ordinário à realização de políticas públicas que (não só, mas além de tudo) contribuam - direta ou indiretamente - para a redução gradativa das mazelas sociais presentes no Brasil contemporâneo. A principal consequência percebida nesse diapasão foi o aumento (ou acúmulo) das funções institucionais do Poder Judiciário. ${ }^{21}$

Dentro dessa perspectiva, a judicialização dos direitos sociais "quando mantida em níveis aceitáveis, pode até ser benéfica para a

19 BARCELLOS, Ana Paula de. Neoconstitucionalismo, Direitos Fundamentais e Controle das Políticas Públicas. Revista de Direito Administrativo: Repositório FGV de Periódicos e Revistas, Rio de Janeiro, v. 240, 2005, p. 102.

${ }^{20}$ BARROSO, Luís Roberto. O controle de constitucionalidade no direito brasileiro. 6 . ed. são Paulo: Saraiva, 2014, p. 366.

${ }^{21}$ OLIVEIRA, Rafael Thomaz de; TASSINARI, Clarissa. Judicialização da política e ativismo judicial: notas para uma necessária diferenciação. In: Antônio Pereira Gaio Júnior; Márcio Gil Tostes dos Santos. (Org.). Constituição Brasileira de 1988: Reflexões em Comemoração ao seu 25.․ Aniversário. 1. ed. Curitiba: Juruá, 2014, p. 81. 
sobrevivência democrática das instituições e para a garantia efetiva do pacto constitucional." 22

Diante da incapacidade dos órgãos políticos em cumprir suas obrigações sociais, o Poder Judiciário adquire legitimidade para sanar as lacunas deixadas pelos entes estatais, a fim de garantir a efetividade das normas constitucionais e concretizar a justiça social. Assim, o judiciário não pode formular e executar políticas públicas, no entanto, pode controlá-las sob o aspecto constitucional, especificamente no que tange ao núcleo dos direitos fundamentais.

\section{A RESERVA do POSSÍVEL}

Importante, nesse particular, conceituar a reserva do possível, por ser um dos principais argumentos apresentados pelo Estado em desfavor dos direitos prestacionais. Oriunda de uma decisão do Tribunal Constitucional Alemão sobre a restrição de recursos para acesso ao ensino superior, a alegação da cláusula da reserva do possível é baseada na ideia de que a prestação material de serviços públicos está sujeita à condição da disponibilidade dos respectivos recursos econômicos.

A disponibilidade desses recursos estaria localizada no campo discricionário das decisões políticas, através da composição dos orçamentos públicos. É, portanto, associada à alegação de insuficiência de recursos financeiros como escusa genérica dos entes estatais para se eximir do cumprimento de suas obrigações no âmbito dos direitos sociais:

A teoria da "reserva do possível" é condicionada pelas disponibilidades orçamentárias, porém os legisladores não possuem ampla liberdade de conformação, pois estão vinculados ao princípio da supremacia constitucional, devendo implementar os objetivos estabelecidos na Constituição de 1988, que se encontram no art. $3^{\circ}$, dentre outras normas-objetivo. ${ }^{23}$

22 OLIVEIRA, Rafael Tomaz de; FARIA, Bruno Costa; CURTOLO, Cristiane Maria de Lima; TEODORO, Leandro; VELUDO, Michele Seixas; PEREIRA, Joaquim Eduardo. A jurisdição constitucional entre a judicialização e o ativismo: Percursos para uma necessária diferenciação. Anais do X Simpósio Nacional de Direito Constitucional, biênio 2010-2011, p. 304.

23 SCAFF, Fernando Facury. Reserva do possível, mínimo existencial e direitos humanos. Revista Interesse Público. Belo Horizonte, n. 32, 2005, p. 226. 
Tendo em vista que os recursos estatais são, de fato, finitos e, considerando que necessidades dos indivíduos são ilimitadas, a efetivação dos direitos sociais depende da compatibilização dos recursos às necessidades sociais, de maneira a não inviabilizar os demais projetos sociais. Nesse sentido:

Tem-se entendido que em situações extremas as despesas realizadas em função de direitos prestacionais judicialmente impostos inviabilizam outros projetos estatais, e possivelmente até afetaria projetos relacionados a outros direitos fundamentais. Sendo assim, tais prestações, uma vez determinadas pelo Judiciário em favor do autor de ação nesse sentido, poderiam concentrar o aporte de recursos de tal modo que se tornaria impossível estendê-lo a outras pessoas, com evidente "prejuízo ao princípio igualitário". ${ }^{24}$

Com efeito, a cláusula da reserva do possível relaciona-se com a razoabilidade entre a aplicação dos recursos provenientes do orçamento e das pretensões dos indivíduos perante o Estado: os direitos sociais estão sob a reserva do possível somente naquilo que é razoável exigir do Estado e, em última análise, da própria sociedade. Contudo, no Brasil, não costuma referir-se à razoabilidade da pretensão, mas tão-somente à disponibilidade ou não de recursos financeiros.

Segundo Jorge Miranda, os direitos sociais na Constituição Portuguesa estão sujeitos à reserva do possível. Contudo, em interessante lição, ensina que as respectivas normas concretizadoras estão sujeitas a uma reserva geral imanente de interpretação, traduzida em quatro pontos:

24 SILVA, Laís Batistuta; THEODORO, Marcelo Antônio. Custo do direito: apontamentos sobre o conflito entre reserva do possível e mínimo existencial. Conpedi: XXII Encontro Nacional do CONPEDI/UNINOVE, São Paulo, p. 22, 2013. XXII Encontro Nacional do CONPEDI /UNINOVE. Disponível em: $<$ http://www.publicadireito.com.br/artigos/?cod=757c26bb260eb37f $>$. Acesso em: 17 mar. 2017. 
$\left.1^{\circ}\right)$ Quando se verifiquem condições económicas favoráveis, essas normas devem ser interpretadas e aplicadas de modo a de delas extrair o máximo de satisfação das necessidades sociais e a realização de todas as prestações; $2^{\circ}$ ) Ao invés, não ocorrendo tais condições - em especial por causa de recessão ou de crise financeira - as prestações têm de ser adequadas ao nível de sustentabilidade existente, com eventual redução dos seus beneficiários ou dos seus montantes; $3^{\circ}$ ) Situações de extrema escassez de recursos ou de excepção constitucional (estado de sítio ou de emergência) podem provocar a suspensão destas ou daquelas normas, mas elas hão de retomar a sua efectividade, a curto ou a médio prazo, logo que restabelecida a normalidade da vida colectiva - o que não se justifica, em caso algum, é uma leitura a contrário do art. $19^{\circ}$ da Constituição quer no sentido da impossibilidade de suspensão dos direitos económicos, sociais e culturais, quer no sentido de uma eventual suspensão não ter de observar quaisquer regras ou limites, designadamente o respeito da reserva de competência legislativa parlamentar; $4^{\circ}$ ) Mesmo nesses casos a dignidade da pessoa humana postula a garantia de um conteúdo mínimo dos direitos ou de um mínimo material de subsistência. ${ }^{25}$

Portanto, "só é obrigatório o que seja possível, mas o que é possível torna-se obrigatório." 26

\section{DIREITOS SOCIAIS, MÍNIMO EXISTENCIAL E NÃO}

${ }^{25}$ MIRANDA, Jorge. O regime dos direitos sociais. Revista de Informação Legislativa, Brasília, 2010, A. 47, n. 188, p. 34. Artigo 19. Suspensão do exercício de direitos: 1. Os órgãos de soberania não podem, conjunta ou separadamente, suspender o exercício dos direitos, liberdades e garantias, salvo em caso de estado de sítio ou de estado de emergência, declarados na forma prevista na Constituição.

${ }^{26}$ MIRANDA, Jorge. O regime dos direitos sociais. Revista de Informação Legislativa, Brasília, 2010, A. 47, n. 188, p. 34. 


\section{A UNIVERSALIZAÇÃO DOS DIREITOS SOCIAIS E SUA RELEVÂNCIA PARA O EXERCÍCIO E CONCREÇÃO DA CIDADANIA}

\section{RETROCESSO SOCIAL}

A noção de mínimo existencial assume importância nas situações em que o Estado utiliza o argumento da reserva do possível para justificar restrições à efetivação dos direitos fundamentais sociais. Não existe um consenso acerca do conteúdo do mínimo existencial, mas nas palavras de Antônio Agusto Cançado Trindade:

É significativo que já se comece hoje a considerar o que constituiria um "núcleo fundamental" de direitos econômicos, sociais e culturais. Há os que, como a Comissão Interamericana de Direitos Humanos, argumentam que tal núcleo seria constituído pelos direitos ao trabalho, à saúde e à educação. Em recentes reuniões internacionais de peritos também se tem referido, como possíveis componentes daquele núcleo, aos chamados "direitos de subsistência" (e.g., direito à alimentação, direito à moradia, direito aos cuidados médicos e direito à educação). ${ }^{27}$

A ideia de um "mínimo existencial" de J. Rawls acrescenta aos bens primários o caráter político como pressuposto da democracia. Nesse sentido:

[...] o mínimo existencial não pode ser restringido à satisfação das necessidades físicas dos indivíduos, como se a preocupação fosse apenas com a sua sobrevivência, ou o chamado "mínimo vital". Para marcar a estreita relação com a dignidade, o mínimo existencial não pode ser atrelado apenas à satisfação das necessidades básicas materiais, mas deve visar o desenvolvimento da pessoa como cidadã. Nisso há um avanço com a ideia de bens primários. Os direitos à educação básica, à saúde, à alimentação, etc., certamente estão incluídos ou pressupostos no primeiro princípio de justiça. Mas essa lista é completada com outros bens primários do segundo princípio, tal como a igualdade equitativa de

27 TRINDADE, Antônio Augusto Cançado. Tratado de Direito Internacional dos

Direitos Humanos, v I. Porto Alegre: Sergio Antonio Fabris Editor, 1997, p. 493. 
oportunidades, para a qual, aliás, é necessária a educação. Com isso, o conteúdo do princípio da dignidade da pessoa humana é mais completo e a possibilidade do exercício da autonomia mais exequível. ${ }^{28}$

No contexto dos direitos fundamentais, a baliza para o sopesamento do mínimo existencial faz-se considerando o princípio da dignidade humana: não se relaciona apenas a assegurar condições mínimas de sobrevivência, mas condições que assegurem dignidade. O princípio da dignidade da pessoa humana assume função de parâmetro para avaliar o padrão mínimo dos direitos sociais. Nesse sentido, Ingo Sarlet:

Com efeito, quanto mais diminuta a disponibilidade de recursos, mais se impõe uma deliberação democrática a respeito de sua destinação, especialmente de forma a que sejam atendidas satisfatoriamente todas as rubricas do orçamento público, notadamente aquelas que dizem com a realização dos direitos fundamentais e da própria justiça social. Na mesma proporção, deverá crescer o índice de sensibilidade por parte daqueles aos quais foi delegada a difícil missão de zelar pelo cumprimento da Constituição, de tal sorte que - em se tratando do reconhecimento de um direito subjetivo a determinada prestação social - assume lugar de destaque o princípio da proporcionalidade, que servirá de parâmetro no indispensável processo de ponderação de bens que se impõe quando da decisão acerca da concessão, ou não, de um direito subjetivo individual ou mesmo da declaração de inconstitucionalidade de uma medida restritiva dos direitos sociais. ${ }^{29}$

À vista disso, o mínimo existencial contempla direitos imprescindíveis e constitui-se em limitação à reserva do possível "ao delimitar a porção do direito fundamental que não pode ser restringida, nem mesmo sob o fundamento da inexistência de recursos financeiros

${ }^{28}$ EBER, Thadeu. A ideia de um "mínimo existencial" de J. Rawls. Kriterion: Revista de Filosofia, Belo Horizonte, n. 127, p. 209-210, jun. 2013.

29 SARLET, Ingo Wolfgang. Os direitos fundamentais sociais na constituição de 1988. Revista Diálogo Jurídico, Salvador, v. 1, n. 1, p.38-39, 2001. 


\section{A UNIVERSALIZAÇÃO DOS DIREITOS SOCIAIS E SUA RELEVÂNCIA PARA O EXERCÍCIO E CONCREÇÃO DA CIDADANIA}

suficientes, por ser imprescindível à preservação da dignidade do titular do direito." 30

O princípio da proibição do retrocesso social, por sua vez, confere aos direitos fundamentais estabilidade nas conquistas sociais consagradas na constituição - assim "o desenvolvimento atingido não é passível de retrogradação." ${ }^{31}$ Não obstante o dissenso da nomenclatura ${ }^{32}$, a questão da proibição do retrocesso social surgiu em consequência da busca pela efetiva concretização de direitos sociais. O principal objetivo é garantir o núcleo essencial dos direitos fundamentais sociais.

Segundo Ingo Sarlet ${ }^{33}$ o princípio constitucional do não retrocesso social está implícito na Constituição Federal de 1988: decorre do princípio do Estado democrático e social de direito, do princípio da máxima eficácia e efetividade das normas definidoras de direitos fundamentais, da segurança jurídica, da proteção da confiança e, principalmente, da dignidade humana.

Possui conteúdos positivo e negativo. O conteúdo positivo encontrase no dever do legislador de ampliar a concretização dos direitos fundamentais sociais, com vistas ao avanço social. O conteúdo negativo refere-se à não supressão ou redução de direitos fundamentais sociais conquistados:

[...] no plano normativo, a eficácia impeditiva de retrocesso fornece diques contra a mera revogação de

30 MATSUDA, Juliana Tiemi Maruyama; PEREIRA, Helida Maria; SOUZA, Luciana
Camila de. O mínimo existencial como limite à aplicação da reserva do possível aos
direitos fundamentais sociais. p.1-22. $\quad$ Disponível em: <http://www.agu.gov.br/page/download/index/id/ 7306306>. Acesso em: 21 mar. 2017.

${ }^{31}$ ROTHENBURG, Walter Claudius. Direitos Fundamentais e suas características. Revista de Direito Constitucional e Internacional, São Paulo, n. 8, 2000, p. 156.

32 São várias as nomenclaturas: proibição do retrocesso social, vedação do retrocesso social, princípio do não retorno da concretização, proibição da contra revolução social ou da evolução reacionária. Nesse sentido: DERBLI, Felipe. O princípio da proibição do retrocesso social na Constituição de 1988. Rio de Janeiro: Renovar, 2007, p. 199.

33 SARLET, Ingo Wolfgang. O Estado Social de Direito, a Proibição de Retrocesso e a Garantia Fundamental da Propriedade. Revista Eletrônica sobre a Reforma do Estado (RERE), Salvador, Instituto Brasileiro de Direito Público, n. 9, março/abril/maio, 2007. 
normas que consagram direitos fundamentais ou contra a substituição daquela por outras menos generosas para com estes; e, no plano dos atos concretos, a proibição de retrocesso permite impugnar, por exemplo, a implementação de políticas públicas de enfraquecimento dos direitos fundamentais. [...] A eficácia impeditiva de retrocesso vale igualmente para excepcional possibilidade de restrição de direito fundamental que jamais poderá avançar sobre o estágio de desenvolvimento jurídico-normativo por este atingido. ${ }^{34}$

Cabe ressaltar que, em determinadas situações fáticas, será admissível a prevalência de outros princípios sobre a proibição de retrocesso social, através do juízo de ponderação - mas, em regra, inexiste a possibilidade de supressão integral de norma infraconstitucional que consagre um direito social. Em entendimento recente, J. J. Gomes Canotilho posicionou-se contrário à concepção rígida e inflexível do princípio da vedação do retrocesso social, nos seguintes termos:

O rígido princípio da "não reversibilidade" ou, formulação marcadamente ideológica, o "princípio da proibição da evolução reaccionária" pressupunha um progresso, uma direcção e uma meta emancipatória e unilateralmente definidas: aumento contínuo de prestações sociais. Deve relativizar-se este discurso que nós próprios enfatizámos noutros trabalhos. 'A dramática aceitação de 'menos trabalho e menos salário, mas trabalho e salário e para todos', o desafio da bancarrota da previdência social, o desemprego duradouro, parecem apontar para a insustentabilidade do princípio da não reversibilidade social. ${ }^{35}$

Não obstante a possibilidade de relativização do princípio do retrocesso social, o entrelaçamento entre os direitos fundamentais com o

${ }^{34}$ ROTHENBURG, Walter Claudius. Direitos Fundamentais e suas características. Revista de Direito Constitucional e Internacional, São Paulo, n. 8, 2000, p. 156-157.

35 CANOTILHO, José Joaquim Gomes. Estudos sobre Direitos Fundamentais. Coimbra: Almedina, 2004, p. 111. 
princípio do não retrocesso social, restou consignada a obrigação imposta pela Constituição aos poderes públicos, no sentido de concretizarem, material e normativamente, direitos sociais para propiciar o processo civilizatório de defesa à dignidade da pessoa humana.

O não retrocesso social constitui-se "não apenas em salvaguarda do Estado social de Direito" ${ }^{36}$ ou da "justiça material, mas principalmente da própria dignidade humana, valor guia de toda ordem constitucional e objetivo permanente de toda ordem que se pretenda legítima." ${ }^{37}$

Dessa maneira, a evolução histórica dos direitos humanos, a sua constitucionalização para garantia como direitos fundamentais juntamente com as garantias do mínimo existencial e do não retrocesso social - representam "significativo patamar de democracia social." ${ }^{38}$.

\section{DIREITOS SOCIAIS E CIDADANIA: ANÁLISE À LUZ DO PENSAMENTO DE THOMAS MARSHALL E JOSÉ MURILO DE CARVALHO}

A cidadania é extraída do status ativo dos direitos individuais, haja vista corresponder a liberdade individual de participação da tomada de rumos da sociedade. Marshall ${ }^{39}$ contempla três elementos básicos da cidadania: direitos civis, relacionados aos direitos necessários à liberdade individual, ligados às questões de justiça; direitos políticos, referentes às participação do exercício do poder político, afeto ao parlamento; e direitos sociais, afetos ao mínimo de bem-estar econômico e segurança do direito de participar, ligado aos serviços sociais.

\footnotetext{
36 SARLET, Ingo Wolfgang. O Estado Social de Direito, a Proibição de Retrocesso e a Garantia Fundamental da Propriedade. Revista Eletrônica sobre a Reforma do Estado (RERE), Salvador, Instituto Brasileiro de Direito Público, n. 9, março/abril/maio, 2007, p. 20.

${ }^{37}$ SARLET, Ingo Wolfgang. O Estado Social de Direito, a Proibição de Retrocesso e a Garantia Fundamental da Propriedade. Revista Eletrônica sobre a Reforma do Estado (RERE), Salvador, Instituto Brasileiro de Direito Público, n. 9, março/abril/maio, 2007, p. 20.

${ }^{38}$ DELGADO, Maurício Godinho. Capitalismo, trabalho e emprego: entre o paradigma da destruição e os caminhos de reconstrução. São Paulo: LTr, 2006, p. 128.

39 MARSHALL, Thomas Humprey. Cidadania, classe social e status. Rio de Janeiro: Zahar Editores, 1967, p. 63.
} 
Para Marshall a "cidadania é um status concedido àqueles membros integrais de uma comunidade" 40 - por conseguinte, consiste num pressuposto da "igualdade humana básica de participação." ${ }^{41} \mathrm{~A}$ incorporação dos direitos sociais ao status de cidadania visa, verdadeiramente, modificar o padrão de desigualdade social. Isso porque, consoante "a desigualdade do sistema de classes pode ser aceitável desde que a igualdade de cidadania seja reconhecida." ${ }^{42}$ Essa é uma condição fundamental para que o Estado adquira um caráter democrático.

Verifica-se, desse modo, que cidadania segundo Marshall vai além do conceito tradicional de liberdade de participação. $\mathrm{O}$ autor preocupa-se com a efetividade do status cidadania e, principalmente, com a igualdade dos cidadãos no acesso aos direitos independentemente das várias classes sociais.

Sobre a concretização dos diretos sociais, é sabido que a figura do Estado provedor, fundado em um paradigma social, tenciona suprir as necessidades básicas dos cidadãos, notadamente nas áreas da saúde e da educação. A propósito, Marshall ${ }^{43}$ sustenta que o direito à liberdade de palavra não se justifica se, devido à falta de educação, o indivíduo não tem nada a dizer. Isto é, não basta a previsão legal de direitos, a cidadania necessita de políticas públicas para sua plenitude.

Nesse propósito, cumpre ao Estado viabilizar programas sociais aos que se encontram marginalizados. No entanto, tais programas governamentais, tem por finalidade reduzir o ônus da pobreza e alterar o padrão de desigualdade.

No Brasil, em decorrência do peso histórico do Brasil-colônia e, portanto, dos entraves ao seu desenvolvimento, os direitos sociais de cidadania desenvolveram-se tardiamente. Os direitos sociais foram introduzidos no governo Vargas, num momento de supressão dos direitos políticos e não em decorrência da luta política organizada dos movimentos sociais - portanto, com inversão da ordem proposta por Marshall. Nesse sentido, José Murilo Carvalho:

40 MARSHALL, Thomas Humprey. Cidadania, classe social e status. Rio de Janeiro: Zahar Editores, 1967, p. 76.

${ }^{41}$ MARSHALL, Thomas Humprey. Cidadania, classe social e status. Rio de Janeiro: Zahar Editores, 1967, p. 62.

42 MARSHALL, Thomas Humprey. Cidadania, classe social e status. Rio de Janeiro: Zahar Editores, 1967, p. 62.

43 MARSHALL, Thomas Humprey. Cidadania, classe social e status. Rio de Janeiro: Zahar Editores, 1967, p. 73. 


\title{
A UNIVERSALIZAÇÃO DOS DIREITOS SOCIAIS E SUA RELEVÂNCIA PARA O EXERCÍCIO E CONCREÇÃO DA CIDADANIA
}

\begin{abstract}
Era avanço na cidadania, na medida em que trazia as massas para política. Mas em contrapartida, colocava os cidadãos em posição de dependência perante os líderes, aos quais votavam lealdade pessoal pelos benefícios que eles de fato ou supostamente lhes tinham distribuído. A antecipação dos direitos sociais fazia com que os direitos não fossem vistos como tais, como independentes da ação do governo, mas como um favor em troca do qual se deviam gratidão e lealdade. A cidadania que daí resultava era passiva e receptora antes que ativa e reivindicadora. ${ }^{44}$
\end{abstract}

Diante dessa conjuntura, o descompasso existente entre as políticas sociais e o status de cidadania, impossibilita a denominada "igualdade humana básica associada ao conceito de participação integral na sociedade" idealizada por Marshall.

A cidadania substancial é verificada a partir da influência exercida sobre a desigualdade social, contornando-a mediante a aplicação do princípio da igualdade. Aliás, Marshall ${ }^{45}$ considera ser a luta para adquirir direitos o estímulo ao desenvolvimento da cidadania.

Tem-se, portanto, que cidadania relaciona-se não apenas à aquisição de direitos, mas essencialmente à materialização dessas conquistas, sob a ótica do princípio da igualdade, da justiça social e da dignidade da pessoa humana. De acordo com José Murilo de Carvalho, chega-se à conclusão de que no Brasil:

[...] primeiro vieram os direitos sociais, implantados em período de supressão dos direitos políticos e de redução dos direitos civis por um ditador que se tornou popular. Depois, vieram os direitos políticos de maneira também bizarra. A maior expansão do direito do voto deu-se em outro período ditatorial, em que os órgãos de representação política foram transformados em peça decorativa do regime. Finalmente, ainda hoje, muitos direitos civis, a base da sequência de Marshall,

${ }^{44}$ CARVALHO, JOSÉ MURILO. Cidadania no Brasil: o longo caminho. Rio de Janeiro: Civilização Brasileira, 2002, p. 126.

${ }^{45}$ MARSHALL, Thomas Humprey. Cidadania, classe social e status. Rio de Janeiro: Zahar Editores, 1967, p. 69. 
continuam inacessíveis à maioria da população. A pirâmide dos direitos foi colocada de cabeça pra baixo. ${ }^{46}$

No atual estágio de desenvolvimento dos direitos sociais no Brasil, embora a Constituição Federal de 1988 represente, de fato, um importante passo para inclusão e universalização de novos direitos sociais, o distanciamento dos direitos sociais do status de cidadania seja talvez o maior óbice para a implantação de uma cidadania plena.

\section{CONCLUSÃO}

Os dispositivos constitucionais que asseguram direitos sociais não se afiguram como meras declarações de vontade, de natureza estritamente programática: possuem força normativa que assegura sua efetiva implementação através de ações estatais e políticas públicas.

No entanto, em razão da realidade fática, jurídica, social e, principalmente, econômica e orçamentária, os direitos fundamentais não são plenamente concretizados pelos poderes públicos, o que resulta na reivindicação da tutela jurisdicional dos direitos sociais. Neste contexto sociopolítico de judicialização dos direitos fundamentais, questões sociais e políticas relevantes estão sendo decididas, em caráter final, pelo Poder Judiciário.

Não obstante o limite de atuação dos três poderes do Estado deva ser respeitado, não se pode impedir que o poder judiciário atue em consonância com o texto constitucional e demais diplomas legais.

Em tempos da prevalência do princípio da dignidade humana, as omissões dos poderes políticos - Executivo e Legislativo - não podem ser corroboradas pela omissão do Poder Judiciário. Desta feita, o judiciário adquire legitimidade para garantir a efetividade das normas constitucionais e concretizar a justiça social por intermédio da sua atividade jurisdicional, respeitados os limites impostos pela razoabilidade da aplicação dos recursos provenientes dos orçamentos.

Tendo em vista que os recursos estatais são limitados, a efetivação dos direitos sociais depende da compatibilização dos recursos às necessidades sociais, de maneira a não inviabilizar os demais projetos sociais. A cláusula da reserva do possível relaciona-se com a razoabilidade entre a aplicação dos recursos provenientes do orçamento e das pretensões dos indivíduos perante o Estado: os direitos sociais estão

46 CARVALHO, JOSÉ MURILO. Cidadania no Brasil: o longo caminho. Rio de Janeiro: Civilização Brasileira, 2002, p. 219. 
sob a reserva do possível somente naquilo que é razoável exigir do Estado e, em última análise, da própria sociedade.

Neste contexto, a noção de mínimo existencial e o princípio do não retrocesso social assumem importância em situações em que o Estado utiliza o argumento da reserva do possível para justificar restrições à efetivação dos direitos fundamentais sociais: do entrelaçamento entre os direitos fundamentais sociais com o princípio do não retrocesso social, restou consignada a obrigação imposta pela Constituição aos poderes públicos, no sentido de concretizarem, material e normativamente, direitos sociais para propiciar o processo civilizatório de defesa à dignidade da pessoa humana e exercício da cidadania.

Por derradeiro, a perspectiva da conquista da cidadania plena perpassa pela compreensão de que os direitos sociais proclamados no texto constitucional devem pautar o exercício dos poderes do Estado Democrático de Direito. A Constituição Federal de 1988 efetivamente representa um importante passo para inclusão e universalização de novos direitos sociais na esfera da cidadania.

Assim, ainda que o texto constitucional se revista de características universalizantes no que tange aos direitos sociais, observamos que há entraves de natureza política e socioeconômica para sua efetivação que passam pelo caminho da cidadania.

Se José Murilo de Carvalho já apontava no título de seu livro que a cidadania no Brasil era um "longo caminho", tal constatação ainda nos parece verdadeira, tendo em vista que há ainda muito a ser realizado para que seja mitigada a acentuada desigualdade social existente no Brasil, e para o alcance de tal desiderato faz-se necessário a realização de políticas públicas eficazes, e na sua ausência, da participação do Poder Judiciário, visando garantir direitos vitais para as pessoas, sem os quais a dignidade humana fica comprometida.

Nesse panorama, verifica-se que a acepção tradicional de cidadania, atinente à liberdade de participação dos indivíduos na tomada de decisão de interesse da sociedade, foi superada pela perspectiva de cidadania sob o ângulo da judicialização das políticas públicas, exercida mediante os instrumentos de tutela coletiva, objetivando a concreção dos direitos sociais ligados ao mínimo existencial e fundados nos princípios da igualdade, da justiça social e da dignidade da pessoa humana.

Logo, a concreção da cidadania, em face da universalização dos direitos sociais, exigirá ações concretas por parte do Estado e sociedade, neste longo caminho a ser percorrido. 


\section{REFERÊNCIAS}

BARCELLOS, Ana Paula de. Neoconstitucionalismo, Direitos Fundamentais e Controle das Políticas Públicas. Revista de Direito Administrativo: Repositório FGV de Periódicos e Revistas, Rio de Janeiro, v. 240, p. 83-103, 2005. Disponível em: $<$ http://bibliotecadigital.fgv.br/ojs/index.php/rda/article/view/43620/446 97>. Acesso em: 15 mar. 2017.

BARROSO, Luís Roberto. O controle de constitucionalidade no direito brasileiro. 6. ed. são Paulo: Saraiva, 2014.

BOBBIO, Norberto. A Era dos Direitos. Tradução: Carlos Nelson Coutinho. Rio de Janeiro: Campus, 1992.

CANOTILHO, José Joaquim Gomes. Direito Constitucional e Teoria da Constituição. 7 ed. Coimbra: Almedina, 2003.

Almedina, 2004.

Estudos sobre Direitos Fundamentais. Coimbra:

CARVALHO, José Murilo. Cidadania no Brasil: o longo caminho. Rio de Janeiro: Civilização Brasileira, 2002.

DELGADO, Maurício Godinho. Capitalismo, trabalho e emprego: entre o paradigma da destruição e os caminhos de reconstrução. São Paulo: LTr, 2006.

EBER, Thadeu. A ideia de um "mínimo existencial" de J.

Rawls. Kriterion: Revista de Filosofia, Belo Horizonte, n. 127, p.197210, jun. 2013. Disponível em:

$<$ http://www.scielo.br/pdf/kr/v54n127/n127a11.pdf $>$. Acesso em: 12 out. 2017.

FARIA, José Eduardo. Os desafios do Judiciário. Revista USP. São Paulo, n. 21, p. 47-57: Coordenadoria de Comunicação Social (CCS) / USP, 1994.

GOMES, Eduardo Biacchi. Blocos econômicos: solução de controvérsias, uma análise comparativa a partir da união europeia e mercosul. 3. ed. rev. atual. Curitiba: Juruá: 2010. 
LAFER, Celso. A internacionalização dos direitos humanos: constituição, racismo e relações internacionais. São Paulo: Manole, 2005.

MARSHALL, Thomas Humprey. Cidadania, classe social e status. Rio de Janeiro: Zahar Editores, 1967.

MATSUDA, Juliana Tiemi Maruyama; PEREIRA, Helida Maria; SOUZA, Luciana Camila de. $\mathrm{O}$ mínimo existencial como limite à aplicação da reserva do possível aos direitos fundamentais sociais. p.1-22. Disponível em:

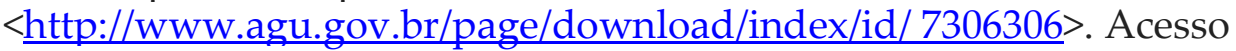
em: 21 mar. 2017.

MIRANDA, Jorge. O regime dos direitos sociais. Revista de Informação Legislativa, Brasília, p.23-36, 2010. Trimestral. A. 47, n. 188. Disponível em:

$<\underline{\text { http://www2.senado.leg.br/bdsf/bitstream/handle/id/198710/000901831 }}$ .pdf>. Acesso em: 25 mar. 2017.

OLIVEIRA, Rafael Thomaz de; TASSINARI, Clarissa. Judicialização da política e ativismo judicial: notas para uma necessária diferenciação. In: Antônio Pereira Gaio Júnior; Márcio Gil Tostes dos Santos. (Org.).

Constituição Brasileira de 1988: Reflexões em Comemoração ao seu 25.ำ Aniversário. 1. ed. Curitiba: Juruá, 2014.

; FARIA, Bruno Costa; CURTOLO, Cristiane Maria de Lima; TEODORO, Leandro; VELUDO, Michele Seixas; PEREIRA, Joaquim Eduardo. A jurisdição constitucional entre a judicialização e o ativismo: Percursos para uma necessária diferenciação. Anais do X Simpósio Nacional de Direito Constitucional, biênio 2010-2011.

PERLATTO, Fernando. A Constituição de 1988: um marco para a História da Nova República brasileira. Contemporâneos, Revista de Artes e Humanidades, n. 3, nov-abril 2009. Disponível em: $<$ http://www.revistacontemporaneos.com.br/n3/pdf/constituicao.pdf $>$ Acesso em: 21. jun. 2016.

PIOVESAN, Flávia. Proteção dos direitos sociais: desafios do ius commune sul-americano. Rev. TST, Brasília, v. 77, n. 4, p.102-139, 2011. 
Trimestral. Disponível em:

$<$ http://siabi.trt4.jus.br/biblioteca/acervo/Doutrina/artigos/Revista do Tribunal Superior do Trabalho/2011/n 4/Proteção dos direitos sociais desafios do ius commune sul-americano.pdf $>$. Acesso em: 15 mar. 2017.

ROTHENBURG, Walter Claudius. Direitos Fundamentais e suas características. Revista de Direito Constitucional e Internacional, São Paulo, n. 8, p.146-157, 2000. Trimestral. Editora Revista dos Tribunais.

SARLET, Ingo Wolfgang. A eficácia dos direitos fundamentais. 8. ed., rev. e atual. Porto Alegre: Livraria do Advogado, 2007.

Os direitos fundamentais sociais na constituição de 1988. Revista Diálogo Jurídico, Salvador, v. 1, n. 1, p.1-46, 2001. Disponível em: $<$ https://www.passeidireto.com/arquivo/6463366/osdireitos-fundamentais-sociais-na-cf-88-ingo-sarlet-2>. Acesso em: 21 mar. 2017.

. O Estado Social de Direito, a Proibição de Retrocesso e a Garantia Fundamental da Propriedade. Revista Eletrônica sobre a Reforma do Estado (RERE), Salvador, Instituto Brasileiro de Direito Público, n. 9, março/abril/maio, 2007. Disponível em $<$ http://www.direitodoestado.com/revista/rere-9-mar\%C3\%87o-2007ingo\%20sarlet.pdf $>$. Acesso em 22 jun. 2015.

SCAFF, Fernando Facury. Reserva do possível, mínimo existencial e direitos humanos. Revista Interesse Público. Belo Horizonte, n. 32, p. 213-226, 2005.

SILVA, Laís Batistuta; THEODORO, Marcelo Antônio. Custo do direito: apontamentos sobre o conflito entre reserva do possível e mínimo existencial. Conpedi: XXII Encontro Nacional do CONPEDI

/UNINOVE, São Paulo, p. 13-29, 2013. XXII Encontro Nacional do CONPEDI /UNINOVE. Disponível em:

$<$ http://www.publicadireito.com.br/artigos/?cod=757c26bb260eb37f $>$. Acesso em: 17 mar. 2017.

TAVARES, André Ramos. Direitos Fundamentais e suas características. Revista de Direito Constitucional e Internacional, São Paulo, n. 8, p. 403-459, 2000. Trimestral. Editora Revista dos Tribunais. 
A UNIVERSALIZAÇÃO DOS DIREITOS SOCIAIS E SUA RELEVÂNCIA PARA O EXERCÍCIO E CONCREÇÃO DA CIDADANIA

TRINDADE, Antônio Augusto Cançado. Tratado de Direito Internacional dos Direitos Humanos. vol. I. Porto Alegre: Sergio Antonio Fabris Editor, 1997.

\section{A UNIVERSALIZAÇÃO DOS DIREITOS SOCIAIS E SUA RELEVÂNCIA PARA O EXERCÍCIO E CONCREÇÃO DA CIDADANIA \\ THE UNIVERSALIZATION OF SOCIAL RIGHTS AND ITS RELEVANCE TO THE EXERCISE OF CITIZENSHIP}

Submetido em: 2017- 06-26 Aceito em: 2018-06-22 